\title{
Power and Resourse Efficient Envoronmentally Safe Technology for Processing Dumps of Technogenic Waste From Ore-Dressing and Processing Enterprises
}

\author{
V.P. Meshalkin ${ }^{1,2}$ and V.I. Bobkov²,3 \\ ${ }^{1}$ Kurnakov Institute of General and Inorganic Chemistry of RAS, Moscow, Russia \\ ${ }^{2}$ D.I. Mendeleev University of Chemical Technology of Russia, Moscow \\ ${ }^{3}$ National Research University "Moscow Power Engineering Institute" Smolensk Branch
}

Corresponding Author:

V.I. Bobkov

vovabobkoff@mail.ru

Published: 31 December 2020

Publishing services provided by Knowledge E

(c) V.P. Meshalkin and V.I.

Bobkov. This article is distributed under the terms of the

commons Attribution License,

which permits unrestricted use and redistribution provided that the original author and source are credited.

Selection and Peer-review under the responsibility of the TECHNOGEN-2019 Conference Committee.

\section{Abstract}

This research proposes a systematic approach for the analysis of volumes, physicochemical, granulometric, lithologic and thermal characteristics of waste from ore-dressing and processing enterprises stored in the dumps (tailing dumps) of ore-dressing and processing plants to assess the economic potential of its use in the system of complex power and resource efficient environmentally safe processing including palletizing machines, conveyor indurating machines and ore-thermal furnaces. The obtained results allow the authors to formulate the basic engineering, technological, economic and environmental requirements for complex chemical and power engineering systems of processing technogenic waste from ore-dressing and processing plants, these results make it also possible to define the degree of variability for the characteristics of the waste lots from various dumps. The paper describes the developed intensional and mathematical formulations for the multiscale problem of optimizing chemical and power engineering processes of technogenic raw materials processing in a complex chemical and power engineering system as a problem for discrete dynamic programming. The distinctive feature of this problem is to take into account the spatio-temporal multistage processing in a moving multilayer mass of pelletized raw material, the intensity of the process of internal moisture transfer and the variables for the control flow of the heat carrier gas. It allows increasing power efficiency by intensifying heat and mass transfer processes of multilayer drying, calcination and sintering. The criterion of the efficiency is the minimum cost of electric and thermal energy spent on processing. The obtained results were used to calculate power efficient environmentally safe processing of technogenic waste from ore-dressing and processing enterprises dumps. It was defined that heat and mass transfer processes are intensified, power consumption is reduced and the quality of the finished product is increased in the conditions of optimal power and resource efficient operation for the processing system.

Keywords: tecnhogenic waste, waste processing, ore-dressing and processing plant, power and resource efficiency, optimization, system analysis, environmentally safety. 
Ore-dressing and processing complex is one of the most developed complexes in modern Russia, but the depletion of mineral raw material base and environmental problems of technogenic raw material storing makes it necessary to involve waste from ore-dressing and processing enterprises into the integrated processing and utilization.

Unused dumps is not only enormous damage for the environment, it is also mineral raw material irretrievably lost being the result of wind and water erosion. Tailing dumps take a special place among the technogenic deposits, fine-dispersed material is stored in the dumps, this fact enhances their susceptibility to wind and water erosion. Tailing dumps occupy big areas, as a result territories, being much more larger than enterprises land allocation, are subjected to pollution, it influences Russian environment significantly. Ore-dressing and processing enterprises dumps represent a powerful raw material base for the production of phosphorus, ferrous and non-ferrous metals; to involve the dumps into processing is of significant interest to the country as a whole.

The purpose of the proposed integrated work is to create a fundamental physicochemical, technological engineering and organizational base of power efficient environmentally safe resource saving processing for waste from ore dressing and processing enterprises, this base will allow processing for the finished grinded raw material accumulated in the dumps into competitive products with added value. It will also allow the enterprises to reduce the amount of recourses allocated to store this waste; to increase significantly the degree of technogenic raw material converting into the finished useful products; to ensure the elimination of tailing dumps and landfills; to reduce negative environmental impact; to improve the quality of life for the population and to make a successful transition to sustainable socio-economic development of our country.

As a result of the implementation of the mentioned fundamental study technogenic waste from ore-dressing and processing enterprises will be valuable secondary raw material for the products with high added value. Unfortunately, Russia imports a huge amount of valuable raw materials which are contained in the waste of ore-dressing and processing plants, they represent the most valuable import-substituting resources.

In recent years the phosphorus and metallurgical industries have come to the conclusion that the advantage of pellets production is not only in the huge amount of ore fines accumulated in the deposits and dumps of ore-dressing and processing enterprises, but also in the possibility of transporting them to almost any distance with a minimum loss [1]. This advantage of the pellets is selected as the main one to forecast the production development. It can be said that raw materials have to be transported in greater volume over long distances, and pellets can be also transported but their transportation is profitable [2, 3]. Understanding of the strengths and weaknesses of this production comes due to the wide theoretical and experimental research, experimental industrial 


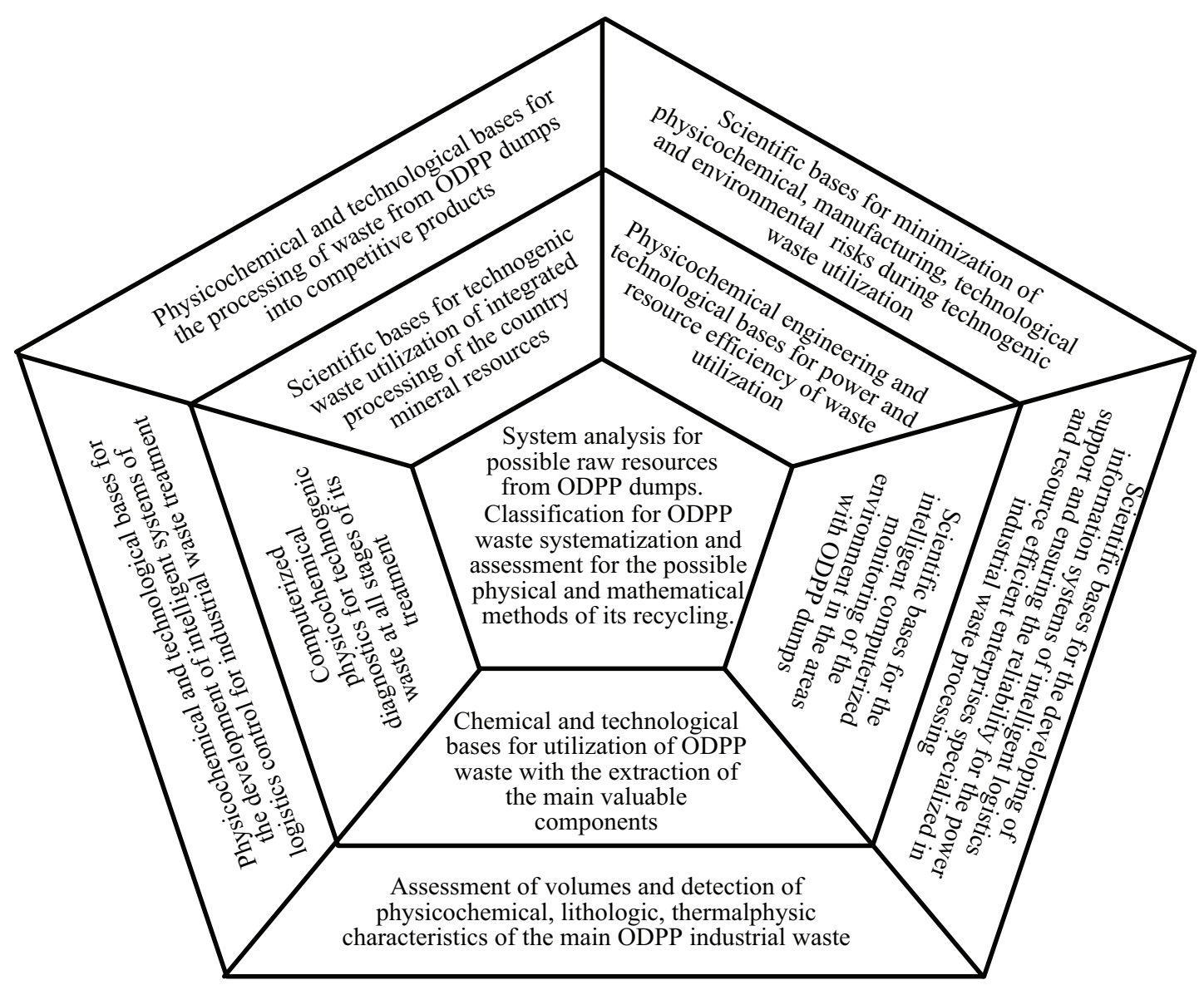

Figure 1: Basic fundamental research developments for the integrated processing program of technogenic waste from the ore-dressing and processing plants (ODPP) dumps.

work, improvement of the engineering design for the main units and equipment [4]. In pellets production there is a lot of experience, many areas of production improvement have been identified, fundamentally new ideas have been expressed, they have already had and will still have a strong influence on the development of ore agglomiration processes [5].

The main reason for the violation of the roasting condition for the pelletized material is a change in the raw pellets properties: humidity, strength, granulometric compositon $[6,7]$. If the pellets with high humidity are fed for roasting with a steady roasting condition this leads to excessive heat and incomplete removal of moisture in the drying zone $[8,9]$. Pellets with an increased amount of moisture in the heating zone are destroyed due to the intense vaporization. As a result a layer is clogged with fines, gas permeability is decreased, the quality becomes worse and the yield of a good product is decreased $[10,11]$. Therefore, the implementation of drying processes in the optimum conditions of power consumption and maximum speed is of great importance for practice [12]. Since technological limitations narrow the range of roasting parameters variation significantly, 


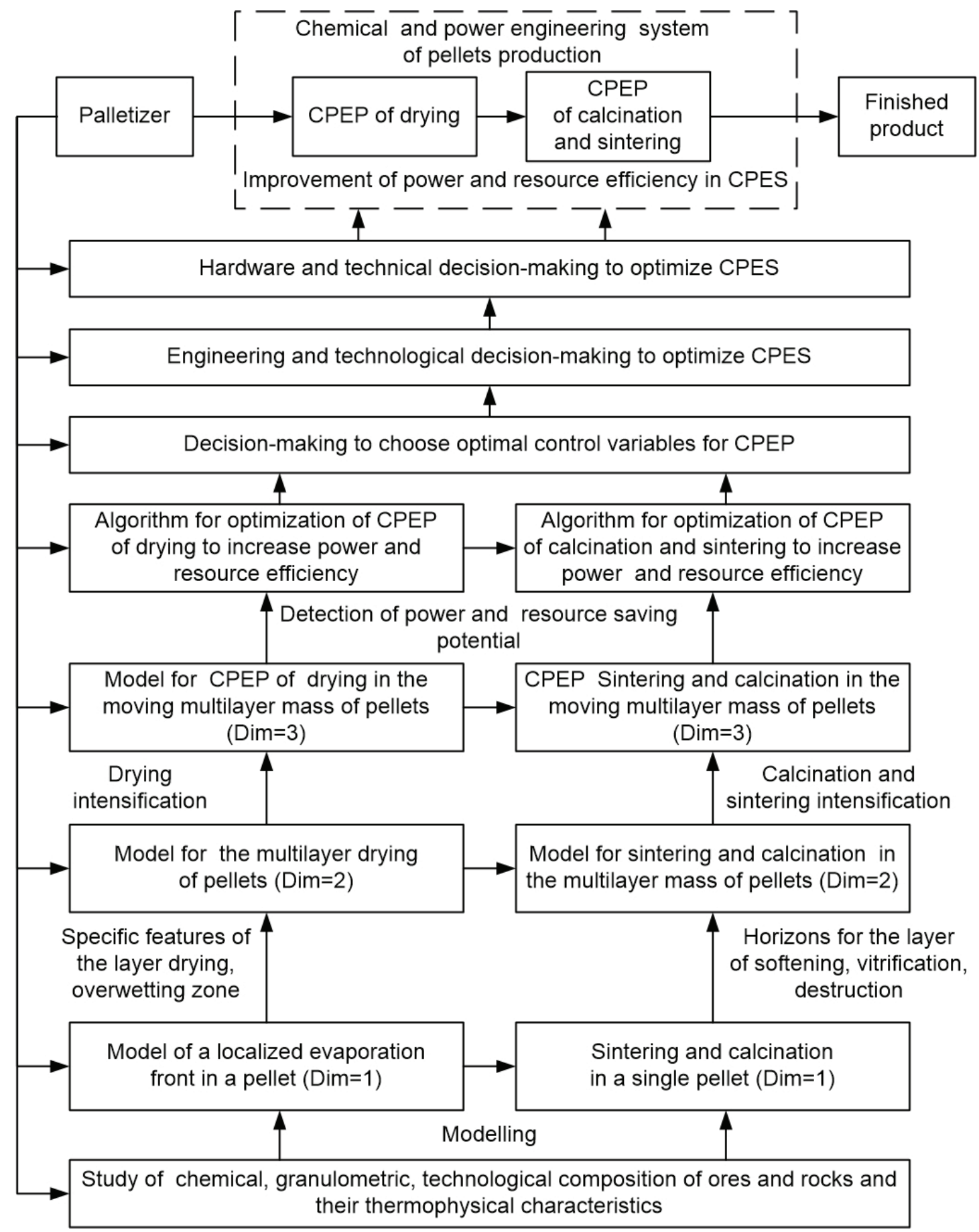

Figure 2: Simplified flowchart of the multiscale modeling algorithm and CPES multilevel optimization for pellets production

a systematic analysis for the mutual influence of all factors determining the condition of pellets roasting is required [13].

The authors developed and presented in [5-7] the multiscale mathematical and computer models and algorithms for the optimal control of the chemical and power engineering system (CPES) of the phosphorite pellets production and multilevel optimization 
according to the criterion of power resource efficiency (fig.2), taking into account the complex structural control scheme of CPES. The developed models and algorithms hierarchically include various levels.

Different levels presence determines the following circumstances. First, the formation of the criterion for power and resource efficiency of CETS pellets roasting involves the indicators such as: completeness for chemical and power engineering process (CPEP) of drying (average moisture content of pellets along the height of the multilayer at the exit of the drying zone); completeness for CPEP of calcination (average degree of response along the height of the multilayer when leaving the high-temperature roasting zone); the completeness of CPEP sintering (the required pellets strength, the average strength of pellets along the height of the layer at the exit from the high-temperature roasting zone); the minimum cost of power consumption for the implementation and completion of these CPEPs $[14,15]$.

Second, it is necessary to discretize CPES according to the time of a moving multilayer mass presence in various local vacuum chambers using the selected criterion to increase power resource efficiency and implement the discrete dynamic programming procedure presented by the authors [5].

Such a systematic approach made it possible to develop methodical, software and information support to make a decision on multilevel optimization of power and resource efficiency of a chemical and power engineering system for pellets production [16], architecture, software and information support, functioning modes of an automated decision support system for optimal control of power resources efficiency of CPES.

The proposed multilevel algorithms for power and resource efficiency of CPES optimization and developed multiscale mathematical models for CPES were realized in practice as a set of programs used to optimize the control of CPES for pellets production. This complex makes it possible to calculate the main thermally activated SPEP occurring in pellets during the high-temperature roasting in the moving multilayer mass on the CPES conveyer. The architecture for the complex of programs for optimization of CPES power and resource efficiency is built according to the modular approach using Borland $\mathrm{C}++$ programming environment for Windows and MathCad software package.

The reported study was funded by RFBR according to the research project № 18-2924094 MK

\section{References}

[1] Bobkov, V. I., et al. (2018). Scientific Basis of Effective Energy Resource Use and Environmentally Safe Processing of Phosphorus-Containing Manufacturing Waste 
of Ore-Dressing Barrows and Processing Enterprises. Clean Technologies and Environmental Policy, vol. 20, issue 10, pp. 2209-2221.

[2] Bustillo, R. M. (2018). Mineral Resources: From Exploration to Sustainability Assessment. Cham: Springer Nature, pp. 96-128.

[3] Shvydkii, V. S., et al. (2018). Mathematical Model of Roasting Process of Ore and Coal Pellets in a Indurating Machine. Institution news. Ferrous metallurgy, vol. 60, issue 4 , pp. $329-335$.

[4] Bragin, V. V., et al. (2014). Relation Between the Productivity and Fuel Consumption in Roasting Machines. Steel in translation, vol. 44, issue 8, pp. 590-594.

[5] Meshalkin, V. P., et al. (2017). Computer Modeling of the Chemical-Power Engineering Process of Roasting of a Moving Multilayer Mass of Phosphorite Pellets. Doklady Chemistry, vol. 477, issue 2, pp. 282-285.

[6] Meshalkin, V. P., et al. (2017). Computer-Aided Modeling of the Chemical Process of Drying of a Moving Dense Multilayer Mass of Phosphorite Pellets. Doklady Chemistry, vol. 475(2), pp. 188-191.

[7] Meshalkin, V. P., et al. (2017). Optimizing the Energy Efficiency of the Chemical and Energy Engineering Process of Drying of a Moving Dense Multilayer Mass of Phosphorite Pellets. Doklady Chemistry, vol. 477, issue 2, pp. 286-289.

[8] Akberdin, A. A., Kim, A. S. and Sultangaziev, R. B. (2018). Experiment Planning in the Simulation of Industrial Processes. Steel in translation, vol. 48, issue 9, pp. 573-577.

[9] Akberdin, A. A., Konurov, U. K. and Sultangaziyev, R. B. (2018). Manganese Capacity and Optical Basicity of Metallurgical Slag. Steel in translation, vol. 48, issue 1, pp. 7-10.

[10] Novichikhin, A. V. and Shorokhova, A. V. Systematic Processing of Iron-Ore Waste in Mining Regions. Steel in trans/ation, vol. 47, issue 7, pp. 456-462.

[11] Leontyev, L. I., Grigorovich, K. V. and Kostina, M. V. (2018). Fundamental Research as a Base of Creating New Materials and Technologies in the Field of Metallurgy. Part 1. Institution news. Ferrous metallurgy, vol. 61, issue 1, pp. 11-22.

[12] Gurin, I. A., et al. (2017). Web Technology in Automated Information and Modeling Systems for Metallurgical Processes. Steel in translation, vol. 47, issue 7, pp. 463-468.

[13] Blank, C. E., Parks, R. W. and Hinman, N. W. (2016). Chitin: A Potential New Alternative Nitrogen Source for the Tertiary, Algal-Based Treatment of Pulp and Paper Mill Wastewater. Journal Applied Phycology, vol. 28, issue 5, pp. 2753-2766.

[14] Bokovikov, B. A., Bragin, V. V. and Shvydkii, V. S. (2014). Role of the Thermal-Inertia Zone in Conveyer Roasting Machines. Steel in Translation, vol. 44, issue 8, pp. 595601. 
[15] Nosov, S. K., et al. (2012). Theoretical Basis, Modern Technologies, and Innovations of Ferrous Metallurgy. Russian Metallurgy (Metally), vol. 2012, issue 12, pp. 1007-1013.

[16] Filatov, S. V., et al. (2017) Improving the Energy Efficiency of Blast Furnaces at PAO NLMK. Steel in Translation, vol. 47, issue 8, pp. 534-537. 